\title{
Análisis comparativo de la responsabilidad social en el sector financiero: estudios de caso en Perú y Brasil 2007-2009
}

\author{
MARTA TOSTES VIEIRA Y \\ LIMBERG CHERO SENMACHE*
}

\begin{abstract}
SUMARIO: RESUMEN.- INTRODUCCIÓN.- I. METODOLOGÍA.- II. PRINCIPALES CONCLUSIONES SOBRE RESPONSABILIDAD SOCIAL.- III. CONCLUSIONES GENERALES.
\end{abstract}

\section{RESUMEN}

El reconocimiento de que la responsabilidad social empresarial (RSE) constituye un medio eficaz para reducir costos y fortalecer la cuota de mercado impulsó estrategias innovadoras en las instituciones financieras que poseen gran capacidad de influencia en la economía y en la política a nivel nacional e internacional. En la búsqueda de una metodología que permita la vigilancia social de la RSE en las empresas peruanas, la Red Puentes aplicó parámetros de comparación de casos en la banca comercial en Perú (2007 y 2009) y Brasil (2007). Tomando en cuenta aspectos relacionados con la implementación de acciones concretas vinculadas a la atención de las necesidades de los consumidores, con el compromiso de los derechos laborales y con la protección medio ambiental, se pudieron analizar cuatro casos peruanos y ocho brasileños, con una escala de criterios de evaluación de 0 a 5 puntos. Sobre la base de los resultados, se puede concluir que ninguno de los casos peruanos presentaron acciones que permitan clasificarlos en un nivel regular de avance, mientras que en Brasil dos casos se destacan: ABN Amro Real y Bradesco. Asimismo, entre 2007 y 2009, en las instituciones financieras peruanas se ha avanzado muy poco en cuanto a la implementación de políticas que impliquen acciones permanentes de medio ambiente y atención a consumidores y trabajadores, aunque se ha podido observar mejorías en este período en Interbank y el Banco de Crédito del Perú.

\section{INTRODUCCIÓN}

Durante las últimas décadas, las organizaciones internacionales se han preocupado por el comportamiento de las empresas transnacionales y el

\footnotetext{
* Marta Tostes Vieira es profesora asociada del Departamento Académico de Ciencias de la Gestión de la PUCP, así como doctora en Ciencias Económicas y Empresariales por la Universidad de Sevilla, España. Limberg Chero Senmache es coordinador del Grupo de Monitoreo del Sector Financiero de Red Puentes, investigador principal de PLADES y economista por la Universidad de Piura. Los autores agradecen a la Red Puentes su autorización para la presente publicación de este trabajo, que actualiza la investigación de TOSTES, Marta (editora). Análisis comparativo de la responsabilidad social en el sector financiero: estudios de caso en Perú y Brasil. Lima: RedLat, PLADES, IDEC, 2007.
} 
impacto de sus acciones sobre los mercados financieros y la economía mundial. Las prácticas de corrupción involucran gobiernos y empresas de diversos sectores, lo que lleva a las organizaciones a buscar mecanismos de presentación de cuentas transparentes, sobre todo en operaciones de accionistas y consumidores. Por su parte, la Organización Internacional para la Normalización (ISO) ha emprendido el desarrollo de una norma internacional que provea una guía para la responsabilidad social, denominada ISO 26000, mediante la cual se busca facilitar estrategias de buenas prácticas de inserción en los mercados internacionales para muchos sectores económicos, en plena fase de globalización.

Con el cambio de siglo, se ha incrementado el número de empresas que han reconocido los beneficios empresariales asociados a las políticas y a las prácticas de RSE. No es la tendencia general de América Latina; pero, en muchos casos, las empresas de la región también se han visto incentivadas a adoptar o a ampliar sus estrategias de RSE como consecuencia de las presiones procedentes de consumidores, proveedores, empleados, comunidades, inversores, organizaciones de activistas y otros actores de su entorno. El resultado de este proceso ha sido una rápida elevación del interés respecto a la RSE en los últimos años, en empresas de diversos tamaños y sectores que buscaron desarrollar estrategias innovadoras e integrarlas con las demás perspectivas del negocio.

Aunque cada vez es mayor el reconocimiento de que la RSE constituye un medio eficaz para reducir costos y fortalecer la cuota de mercado, muchas empresas de la región se han mostrado reticentes a adoptar estas prácticas a causa de una serie de obstáculos. Entre ellos se destaca la poca difusión de las ventajas de la RSE para mejorar el balance final y para reducir riesgos y obligaciones. Otro problema es que no cuentan con expertos locales que puedan ayudarlas a aplicar las medidas de RSE, lo cual se suma a la falta de peticiones por parte de los gobiernos o de los accionistas para revelar públicamente información.

En este contexto, la Red Puentes decide realizar actividades en torno al monitoreo de temas de responsabilidad social en los principales bancos del sistema financiero peruano y brasileños, en el marco de las actividades de la organización para Sudamérica. Red Puentes es una red de ONG y organizaciones sindicales que tiene como objetivo promover la RSE en América Latina desde las perspectivas y las visiones de la sociedad civil, con la finalidad de implementar sus propuestas y de posicionar a estas organizaciones como actores relevantes en el desarrollo de la RSE. Para cumplir con esta labor, la Red Puentes comenzó la tarea de posicionarse en la medición de desempeño de la RSE en la banca comercial con dos de sus organizaciones integrantes: en el Perú, con el Programa Laboral de Desarrollo - PLADES, y, para activar la comparación del caso peruano, se seleccionó a Brasil como la experiencia más cercana y paradigmática de desarrollo del sistema financiero, para lo cual solicitó el apoyo del Instituto Brasileño de Defensa del Consumidor - IDEC. 
El IDEC es una organización de consumidores fundada en 1987, que no persigue fines lucrativos y que no tiene vínculos con empresas, gobiernos o partidos políticos. Tradicionalmente, realiza evaluaciones comparativas de productos y servicios y, en la actualidad, viene buscando perfeccionar una metodología para evaluar la responsabilidad social, de tal forma que el consumidor pueda comparar el comportamiento responsable de las empresas y, de esta manera, premiarlas o punirlas en sus opciones.

Por su parte, PLADES es una ONG peruana, fundada en 1991 para abordar la problemática laboral del país y de la región andina, que promueve el fortalecimiento de las organizaciones sindicales y la vigilancia social de estándares laborales reconocidos en los instrumentos internacionales vigentes, al incorporar una perspectiva de equidad de género y contribuir a la construcción de un modelo global de desarrollo solidario, justo y democrático. Actualmente, trabaja junto a IDEC en el desarrollo de la metodología de evaluación de la responsabilidad social como un instrumento para el logro de sus objetivos institucionales.

El interés del presente documento se centra en realizar un aporte metodológico y casuístico sobre la valoración de las prácticas de RSE al analizar los casos de la banca comercial de Perú y de Brasil para verificar los niveles de cumplimiento de estos criterios, sobre todo en el ámbito de los derechos laborales, de los temas ambientales y de las relaciones con los consumidores.

\section{METODOLOGÍA}

La metodología utilizada en la investigación se ha enfocado en las siguientes líneas estratégicas: el seguimiento y el monitoreo de empresas, la relación sociedad civil-empresa-estado, el fortalecimiento de la sociedad civil, y la incidencia en normas e instrumentos nacionales e internacionales de RSE. En primer lugar, es importante tener en cuenta el concepto de RSE utilizado en cada estudio. Para el caso brasileño, IDEC afirma que:

La Responsabilidad Social es una postura ética permanente de las empresas en el mercado de consumo y en la sociedad. Mucho más que acciones sociales y filantropía, la responsabilidad social, en nuestro entendimiento, debe ser el supuesto y la base de la actividad empresarial y de consumo. Abarca la preocupación y el compromiso con los impactos causados a los consumidores, medio ambiente y trabajadores; los valores profesados en la acción práctica cotidiana en el mercado de consumo - reflejada en la publicidad y en los productos y servicios ofrecidos-; la postura de la empresa en búsqueda de soluciones para eventuales problemas; y, además, la transparencia en las relaciones con los involucrados en sus actividades ${ }^{1}$. 
Para el caso peruano, PLADES señala que:

La Responsabilidad Social Empresarial (RSE) es una perspectiva sobre la empresa que concibe el respeto a los valores éticos, a las personas, a las comunidades y al medio ambiente como elementos de una estrategia integral que incrementa el valor añadido y, por lo tanto, mejora la situación competitiva de la empresa. La RSE se trata así, de un conjunto comprensivo de políticas, prácticas y programas, que se incorporan a todas las operaciones y procesos de toma de decisión empresariales².

Como perspectiva de la presente investigación, se privilegia un enfoque de investigación con análisis de casuística para establecer vínculos con empresas y organismos empresariales sobre la base de datos e investigaciones que interpelen sus compromisos y sus prácticas de RSE en forma pública. Se busca con ello lograr la consolidación de compromisos que mejoren las prácticas existentes y que promuevan nuevas iniciativas. En este sentido, se propuso el monitoreo del sector financiero en Brasil y en el Perú como parte de las actividades relacionadas con el seguimiento, la evaluación y la información del sector empresarial, especialmente de grupos de vigilancia social de organizaciones de la sociedad civil. Es importante resaltar que se realizó el estudio comparativo entre Perú y Brasil durante 2007, a partir de lo que se sentaron los parámetros para que se continúe evaluando el caso peruano, lo cual permitió continuar con la investigación para el año 2009.

De esta manera, la metodología se circunscribe al sector financiero, más específicamente en la banca comercial, y en este marco se procede a la búsqueda de información en las páginas web de cada institución financiera y a la revisión del cumplimiento de sus normas. Asimismo, se ha aplicado una encuesta a los doce casos analizados, lo cual permitió conseguir datos primarios, complementados con el seguimiento de las acciones de los consumidores, los trabajadores y las autoridades medio ambientales.

\subsection{Sector financiero}

La investigación define al sector financiero como el conjunto de empresas dedicadas a la intermediación financiera, de la cual se selecciona a la banca comercial por considerarse que sus operaciones generan impactos significativos en el mundo empresarial, especialmente en la conducción nacional e internacional de los flujos financieros. En este proceso, se difunden buenas prácticas en una actividad económica altamente rentable, cuya imagen institucional depende de los resultados obtenidos en materia de RSE.

2 PLADES. En <http://sisviso.plades.org.pe/sisviso/temasinteres.jsp>. Fecha de consulta: enero de 2007. 
Las instituciones financieras son responsables por diferentes tipos de servicios a nivel nacional e internacional: operaciones de concesión de crédito a personas naturales y empresas, movimientos de cuenta corriente y cobranza de tarifas, movimientos del mercado accionario, emisiones de títulos, entre otros. Todos estos servicios son de extrema importancia para la vida cotidiana de millones de consumidores cada vez más exigentes sobre las prácticas de las empresas que los atienden.

En este sentido, se reconoce que estas instituciones deben financiar proyectos privados que mejoren el comportamiento ambiental de las empresas, lo cual puede ser altamente rentable. Entre otros aspectos, también influyen positivamente al evitar prácticas fraudulentas en el mercado de acciones, al promover un comportamiento laboral apropiado, al impedir la corrupción y el lavado dinero, y al incentivar la difusión de leyes de protección y defensa de los consumidores.

También se observa su intervención en el ámbito político, debido a que los bancos representan uno de los grupos de interés que más financia actividades políticas, en Brasil, y muestran gran influencia, en el caso peruano. Las implicancias de este tipo de acciones pueden generar impactos significativos sobre las decisiones de políticas nacionales como, por ejemplo, favorecer a un sector en detrimento de otros. Finalmente, un aspecto fundamental para caracterizar al sector financiero se centra en el análisis de los reclamos de los órganos de defensa del consumidor.

\section{I.2. Criterios de selección de la muestra}

Al llevar a cabo la investigación, se determinaron diversos criterios para seleccionar la muestra en el sistema financiero en Brasil y Perú. El primer parámetro en el caso brasileño fue que las instituciones elegidas poseyeran más de un millón de clientes en el país, sin considerar los bancos del Estado y aquellos con cartera comercial restringida.

De esta manera, en Brasil fueron elegidos ocho bancos: ABN Amro Real, Banco de Brasil, Bradesco, Caixa Económica Federal, HSBC, Itaú, Santander y Unibanco. En el Perú, se escogieron cuatro bancos de banca múltiple: el Banco de Crédito del Perú (BCP), Banco Internacional del Perú (Interbank), Banco Continental del Perú (BBVA), y Scotiabank. Se tomó la línea de base del año 2006 para verificar la posibilidad de actualización de la muestra. 
Cuadro 1. Brasil: Ranking de principales bancos, 2006

\begin{tabular}{|c|c|c|c|c|c|c|}
\hline \multicolumn{2}{|l|}{ Años } & \multirow{2}{*}{ Banco } & \multirow{2}{*}{$\begin{array}{l}\text { Origen de } \\
\text { capital }\left({ }^{*}\right)\end{array}$} & \multirow{2}{*}{$\begin{array}{c}\text { Activo Total en } \\
\text { millones de } \mathrm{R} \$ \\
\left({ }^{*}\right)\end{array}$} & \multirow{2}{*}{$\begin{array}{c}\text { Depósitos en } \\
\text { millones de R\$ } \\
\left({ }^{*}\right)\end{array}$} & \multirow{2}{*}{$\begin{array}{l}\text { Total de } \\
\text { clientes }\end{array}$} \\
\hline 2006 & 2005 & & & & & \\
\hline 1 & 1 & Banco do Brasil & Brasil & $296.356,40$ & $158.841,00$ & 22.917.936 \\
\hline 2 & 2 & Bradesco & Brasil & $265.547,30$ & $83.905,20$ & \begin{tabular}{|l|}
19.708 .672 \\
\end{tabular} \\
\hline 3 & 4 & Itaú & Brasil & $209.691,20$ & $61.172,90$ & 11.883.221 \\
\hline 4 & 3 & \begin{tabular}{|ll} 
Caja & Económica \\
Federal & \\
\end{tabular} & Brasil & $209.532,80$ & 121.390 .5 & 32.835 .376 \\
\hline 5 & 7 & ABN Amro Real & Holanda & \begin{tabular}{|l|}
$120.830,60$ \\
\end{tabular} & $55.000,80$ & 7.185 .268 \\
\hline 6 & 6 & Santander & España & \begin{tabular}{|l|}
$107.185,70$ \\
\end{tabular} & $31.745,60$ & 8.039 .086 \\
\hline 7 & 5 & Unibanco & Brasil & $103.777,90$ & $35.632,60$ & 9.395 .083 \\
\hline 8 & 8 & HSBC & Inglaterra & $58.265,70$ & $37.725,10$ & 2.518 .488 \\
\hline \multicolumn{4}{|c|}{ Total General } & $1.371 .187,60$ & $464.023,20$ & 114.483 .130 \\
\hline
\end{tabular}

Fuentes: Revista Valor Financiero, «Todo sobre el sistema financiero nacional», junio de 2007; y página web del Banco Central de Brasil. Ranking de las instituciones con más reclamos y con más de un millón de clientes. Los datos mostrados corresponden a noviembre de 2007.

Para la selección de la muestra en el sistema financiero peruano se tuvieron en cuenta los créditos directos, los depósitos totales y el patrimonio de los cuatro principales bancos para 2006 — para el estudio de 2007y 2009 — para el monitoreo de aquel año—. Durante ambos períodos, los cuatro bancos líderes fueron los mismos: BCP, BBVA, Scotiabank e Interbank.

Cuadro 2. Perú: Ranking de créditos, depósitos y patrimonioa/, al 31 de diciembre de 2006 y 2009 (en miles de nuevos soles)

\begin{tabular}{|c|c|c|c|c|c|c|c|c|c|}
\hline & & & 06 & & & & 20 & 09 & \\
\hline réd & os Directos & & & & & & & & \\
\hline Puesto & $\begin{array}{l}\text { Nombre de } \\
\text { la Empresa }\end{array}$ & Monto & $\begin{array}{c}\text { Participación } \\
(\%)\end{array}$ & $\begin{array}{l}\text { Porcentaje } \\
\text { Acumulado }\end{array}$ & Puesto & $\begin{array}{l}\text { Nombre de } \\
\text { la Empresa }\end{array}$ & Monto & $\begin{array}{c}\text { Participación } \\
(\%)\end{array}$ & $\begin{array}{l}\text { Porcentaje } \\
\text { Acumulado }\end{array}$ \\
\hline 1 & $\mathrm{BCP}$ & 14.549 .223 & 30,54 & 30,54 & 1 & $\mathrm{BCP}$ & 29.897.257 & 33,37 & 33,37 \\
\hline 2 & $\begin{array}{l}\text { BBVA Banco } \\
\text { Continental }\end{array}$ & 12.953 .177 & 27,19 & 57,72 & 2 & $\begin{array}{l}\text { BBVA Banco } \\
\text { Continental }\end{array}$ & 20.999 .689 & 23,44 & 56,81 \\
\hline 3 & $\begin{array}{l}\text { Scotiabank } \\
\text { Perú }\end{array}$ & 7.754 .977 & 16,28 & 74,00 & 3 & $\begin{array}{l}\text { Scotiabank } \\
\text { Perú }\end{array}$ & 13.574 .277 & 15,15 & 71,96 \\
\hline 4 & Interbank & 4.419 .321 & 9,28 & 83,27 & 4 & Interbank & 10.196 .811 & 11,38 & 83,34 \\
\hline 5 & Citibank & 1.976 .790 & 4,15 & 87,42 & 5 & Mibanco & 3.007 .221 & 3,36 & 86,69 \\
\hline Depó & sitos Totales & & & & & & & & \\
\hline Puesto & $\begin{array}{l}\text { Nombre de } \\
\text { la Empresa }\end{array}$ & Monto & $\begin{array}{c}\text { Participación } \\
(\%)\end{array}$ & $\begin{array}{l}\text { Porcentaje } \\
\text { Acumulado }\end{array}$ & Puesto & $\begin{array}{l}\text { Nombre de } \\
\text { la Empresa }\end{array}$ & Monto & $\begin{array}{c}\text { Participación } \\
\text { (\%) }\end{array}$ & $\begin{array}{l}\text { Porcentaje } \\
\text { Acumulado }\end{array}$ \\
\hline 1 & $\mathrm{BCP}$ & 20.643 .890 & 36,24 & 36,24 & 1 & $\mathrm{BCP}$ & 32.558 .499 & 34,21 & 34,21 \\
\hline 2 & B. Continental & 13.954 .261 & 24,50 & 60,74 & 2 & $\begin{array}{l}\text { BBVA Banco } \\
\text { Continental }\end{array}$ & 21.085 .462 & 22,15 & 56,36 \\
\hline 3 & $\begin{array}{l}\text { Scotiabank } \\
\text { Perú }\end{array}$ & 9.659 .072 & 16,96 & 77,69 & 3 & $\begin{array}{l}\text { Scotiabank } \\
\text { Perú }\end{array}$ & 15.447 .561 & 16,23 & 72,59 \\
\hline 4 & Interbank & 5.582 .556 & 9,80 & 87,49 & 4 & Interbank & 11.362 .049 & 11,94 & 84,53 \\
\hline 5 & $\mathrm{BIF}$ & 1.905 .967 & 3,35 & 90,84 & 5 & $\mathrm{BIF}$ & 3.186 .710 & 3,35 & 87,88 \\
\hline Patrim & 1onio & & & & & & & & \\
\hline Puesto & $\begin{array}{l}\text { Nombre de } \\
\text { la Empresa }\end{array}$ & Monto & $\begin{array}{c}\text { Participación } \\
(\%)\end{array}$ & $\begin{array}{l}\text { Porcentaje } \\
\text { Acumulado }\end{array}$ & Puesto & $\begin{array}{l}\text { Nombre de } \\
\text { la Empresa }\end{array}$ & Monto & $\begin{array}{c}\text { Participación } \\
(\%)\end{array}$ & $\begin{array}{l}\text { Porcentaje } \\
\text { Acumulado }\end{array}$ \\
\hline 1 & $\mathrm{BCP}$ & 2.860 .879 & 36,34 & 36,34 & 1 & $\mathrm{BCP}$ & 4.827 .551 & 32,81 & 32,81 \\
\hline 2 & $\begin{array}{l}\text { BBVA Banco } \\
\text { Continental }\end{array}$ & 1.710 .651 & 21,73 & 58,06 & 2 & $\begin{array}{l}\text { Scotiabank } \\
\text { Perú }\end{array}$ & 2.954 .039 & 20,08 & 52,89 \\
\hline 3 & $\begin{array}{l}\text { Scotiabank } \\
\text { Perú }\end{array}$ & 1.281 .618 & 16,28 & 74,34 & 3 & $\begin{array}{l}\text { BBVA Banco } \\
\text { Continental }\end{array}$ & 2.887 .676 & 19,63 & 72,52 \\
\hline 4 & Interbank & 668.584 & 8,49 & 82,83 & 4 & Interbank & 1.421 .610 & 9,66 & 82,19 \\
\hline 5 & Citibank & 483.837 & 6,15 & 88,98 & 5 & Citibank & 668.300 & 4,54 & 86,73 \\
\hline
\end{tabular}

Fuente: Superintendencia de Banca y Seguros (SBS).

NOTA (a/): Información obtenida del Balance General reportado a la SBS.

No incluye sucursales en el exterior. 
La presente investigación posee un carácter comparativo tomando como base las informaciones sobre las prácticas de bancos en asuntos relacionados a RSE, que presentan tres fuentes principales. En primer lugar, para la obtención de datos primarios, se utilizó el cuestionario aplicado a funcionarios de los bancos, seleccionados anónimamente según temas afines a sus funciones. En segundo lugar, se analizó la información disponible en formato físico y digital (Internet) sobre documentos de la organización en temas relacionados con RSE, trabajadores y medio ambiente. En tercer lugar, se desarrolló una investigación de campo para el tema de consumidores; para ello, se abrieron cuentas corrientes con el objetivo de observar prácticas o procedimientos de apertura y movimientos, tarifas bancarias, costos de concesión de crédito, servicios de atención al cliente y cajeros electrónicos.

El cuestionario aplicado a los bancos fue elaborado por IDEC con la participación de representantes de organizaciones de la sociedad civil afines, tales como Amigos de Tierra Amazónica Brasilera, Confederación Nacional de Trabajadores del Sector Financiero (CONTRAF/CUT), Centro de Estudios de Relaciones de Trabajo y Desigualdades (CEERT), Programa Laboral de Desarrollo (PLADES/Perú) y Centro de Investigaciones de Empresas Multinacionales de Holanda (SOMO), entre otros.

\section{I.3. Encuesta}

La encuesta contiene 69 preguntas agrupadas en seis bloques, que se caracterizan por ser de tipo cualitativo. El primer bloque tiene como objetivo analizar los bancos a través de información sobre tipos de empresas coligadas, capital accionario, identificación con el banco central, liquidez, número de clientes y puntos de atención en el país. El segundo bloque contiene preguntas generales sobre responsabilidad social, a través de las cuales se busca identificar los conceptos de responsabilidad social en los bancos seleccionados, además de algunas prácticas que evidencien el compromiso de la institución con transparencia y ética. El tercer bloque está concentrado en el tipo de relación que el banco mantiene con trabajadores, representantes de trabajadores y sindicatos acerca de libertad sindical, negociación colectiva, derechos y beneficios de trabajadores directos e indirectos, código de ética y conducta, y relación con las empresas tercerizadas.

Por su parte, el cuarto bloque se enfoca en los consumidores, y es considerado el más importante por IDEC de Brasil: al ser parte del discurso de una institución que desea ser considerada socialmente responsable, resulta fundamental para arribar a las conclusiones de la investigación. El quinto bloque de la encuesta tiene como objetivo identificar si los bancos elegidos poseen una política dirigida hacia el medio ambiente, el desarrollo y el consumo sustentable, así como si mantienen acuerdos de principios internacionales de conducta ética y transparencia. Se busca identificar las condiciones para una política diferenciada por 
seguimientos empresariales para la evaluación de riesgos, a la vez que se garantiza el desarrollo de prácticas con sostenibilidad socioambiental. El último bloque permite verificar qué bancos conducen acciones sociales, empleo de incentivos y deducciones tributarias.

Las preguntas están ordenadas según el bloque de temas de la encuesta, lo cual se puede apreciar en el cuadro 3.

\section{Cuadro 3: Estructura del cuestionario por bloques temáticos para evaluar la RSE}

\begin{tabular}{|c|c|c|}
\hline \multicolumn{2}{|r|}{ Bloques } & Temas \\
\hline 1 & Perfil de banco & Informaciones Institucionales \\
\hline \multirow[t]{3}{*}{2} & \multirow{3}{*}{$\begin{array}{l}\text { Responsabilidad } \\
\text { Social Empresarial }\end{array}$} & Discurso RSE \\
\hline & & Corrupción y transparencia \\
\hline & & Demostraciones financieras, contables y sociales \\
\hline \multirow[t]{5}{*}{3} & \multirow[t]{5}{*}{ Trabajadores } & Libertad y negociación sindical \\
\hline & & Código de Ética y Conduta \\
\hline & & Derechos y beneficios \\
\hline & & $\begin{array}{l}\text { Inclusión / Relación con los trabajadores (direc- } \\
\text { tos e indirectos) }\end{array}$ \\
\hline & & Relación con otras empresas \\
\hline \multirow[t]{3}{*}{4} & \multirow[t]{3}{*}{ Consumidores } & Relación de bancos/consumidores \\
\hline & & Productos y servicios \\
\hline & & Concesión de crédito \\
\hline \multirow[t]{3}{*}{5} & \multirow[t]{3}{*}{ Medio ambiente } & $\begin{array}{l}\text { Políticas de medio ambiente y consumo } \\
\text { sustentable }\end{array}$ \\
\hline & & Adhesión a documentos internacionales \\
\hline & & Concesión de crédito \\
\hline 6 & $\begin{array}{l}\text { Actores sociales, cul- } \\
\text { turales y marketing }\end{array}$ & Filantropía y marketing social \\
\hline
\end{tabular}

Con respecto a la escala de valores, los bloques recibieron una evaluación entre 0 y 5 puntos en cada uno de los subtemas analizados. Las notas corresponden al seguimiento de determinados criterios, mientras que cada a bloque y sus subtemas se les asignan criterios específicos, definidos de acuerdo con la referencia básica descrita en el cuadro 4. 
Cuadro 4: Diccionario de los criterios básicos de evaluación

\begin{tabular}{|l|l|l|}
\hline Nota & Evaluación & \multicolumn{1}{c|}{ Criterio básico } \\
\hline 0 & SR & Sin respuesta o se negó a responder. \\
\hline 1 & Pésimo & $\begin{array}{l}\text { No declara cumplir lo esencial o nada. No demuestra pre- } \\
\text { ocupación con el tema. }\end{array}$ \\
\hline 2 & Malo & $\begin{array}{l}\text { Realiza algunas acciones en relación al tema, más de for- } \\
\text { ma puntual en aspectos de menor relevancia. }\end{array}$ \\
\hline 3 & Regular & $\begin{array}{l}\text { Atiende o prevé una legislación y o a lo mínimo éticamen- } \\
\text { te aceptable. }\end{array}$ \\
\hline 4 & Bueno & $\begin{array}{l}\text { Presenta avances sistemáticos que van más allá de la le- } \\
\text { gislación y /o de lo mínimo de consideraciones esperadas. } \\
\text { Muestra evidencias consistentes y verificables de sus ac- } \\
\text { ciones. }\end{array}$ \\
\hline 5 & Excelente & $\begin{array}{l}\text { Atiende a lo considerado como ideal de comportamiento } \\
\text { en el tema. Presenta evidencias efectivas en documentos y } \\
\text { acciones, asimismo como planes para que se perfeccionen. }\end{array}$ \\
\hline
\end{tabular}

ANÁLISIS COM-

PARATIVO DE LA

RESPONSABILI-

DAD SOCIAL EN EL

SECTOR FINANCIE-

RO: ESTUDIOS DE

CASO EN PERÚ Y

BRASIL 2007-2009

Los temas validados (trabajadores, medio ambiente y consumidores) fueron analizados sobre la base de los siguientes aspectos:

- Características del comportamiento laboral. Se toma en cuenta el respeto a los derechos de los trabajadores con prácticas que amplíen sus beneficios, que respeten la libertad sindical y la negociación colectiva, que mantengan canales efectivos de diálogo con los trabajadores, y que valoren la diversidad de género y los portadores de deficiencia, en las relaciones con trabajadores tanto directos como indirectos (tercerizados).

- Acciones de RSE vinculadas a la difusión de los principios de la gestión sostenible del medio ambiente. Se buscó analizar los aspectos vinculados a la sustentabilidad socioambiental. Ello también puede ser aplicado en la cartera de activos y en la concesión de créditos, sobre todo para evitar el financiamiento de proyectos empresariales que podrían causar daños al medio ambiente, sin las respectivas actividades de mitigación.

- Consumidores. Se observó que las instituciones desarrollasen acciones para informar a los consumidores de forma concreta y transparente sobre los productos y los servicios ofrecidos. También se analizó si estas velaban por el relacionamiento con el consumidor al establecer canales de comunicación y resolución de problemas eficientes, al cuidar la concesión del crédito y al evitar el riesgo de su endeudamiento excesivo, además de promover la inclusión de los consumidores más pobres en el mercado y de proteger la accesibilidad para los portadores de deficiencia. 
Como se observa en el cuadro 3, las preguntas fueron agrupadas en bloques. Cada conjunto presenta una definición de los criterios para la validación de las respuestas y se aplicó una ponderación al bloque que sirvió para componer un ranking de los bancos. IDEC considera que todos los temas abordados en el cuestionario son relevantes para validar el comportamiento socialmente responsable de los bancos; sin embargo, no existe información de todas sus prácticas en todos los temas capaces de servir como referencia para que los consumidores puedan formar su opinión al respecto. Finalmente, para una segunda revisión de los criterios definidos y los principales parámetros de evaluación, se invitó en el caso brasileño a algunos colaboradores para un debate previo ${ }^{3}$.

\section{PRINCIPALES CONCLUSIONES SOBRE RESPONSABILIDAD SOCIAL}

\section{II.1. Banca de Brasil durante 2007}

En Brasil, con frecuencia la responsabilidad social empresarial es confundida con prácticas de filantropía, voluntariado o marketing social. El Instituto Brasileño de Defensa al Consumidor reconoce la importancia de este tipo de acciones, pero considera que son insuficientes para indicar RSE. A continuación, se presentan los resultados de la aplicación de los criterios seleccionados sobre el desarrollo de la RSE a ocho bancos.

En la relación con los trabajadores y la responsabilidad social interna, las mejores calificaciones fueron para Itaú, ABN Amro Real y Bradesco, mientras que las peores calificaciones señalan a los bancos Unibanco y el HSBC. Itaú mantiene coherencia entre su discurso y sus prácticas, pues presenta una agenda constante de reuniones con los líderes sindicales y extiende los beneficios de convenios colectivos a los empleados tercerizados. La peor calificación fue la de Unibanco; esta se debe a la ausencia de políticas de diversidad y al mal indicador de baja presencia de personas con discapacidad en el cuadro funcional.

El ABN Amro Real destacó en las actividades realizadas en torno a la conservación del medio ambiente debido a sus políticas e incentivos al consumo sustentable, entre las que se pueden destacar las siguientes:

- incentivos al uso de materiales reciclados;

- establecimiento de fondos éticos; y

- programas internos de ecoeficiencia con indicadores y metas.

3 Fueron entrevistados Lisa Gunn, de IDEC Brasil, miembro del equipo de monitoreo del sector financiero de Red Puentes; Odilon Faccio, de la revista Primer Plano; Arlene Montanari, de la Confederación Nacional de Trabajadores del Sector Financiero - CONTRAF; Marcus Vinicius, del Departamento Intersindical de Estadística y Estudios Socioeconómicos - DIEESE; Mario Rogerio, del Centro de Estudios de Relaciones de Trabajo y Desigualdades - CEERT; y Gustavo Pimentel, de Amigos de Tierra. Agradecemos su colaboración a los especialistas y resaltamos que no son responsables por posibles resultados no deseados de la presente investigación. 
Cuadro 5. Brasil: Calificación de los casos de RSE en la Banca, 2007

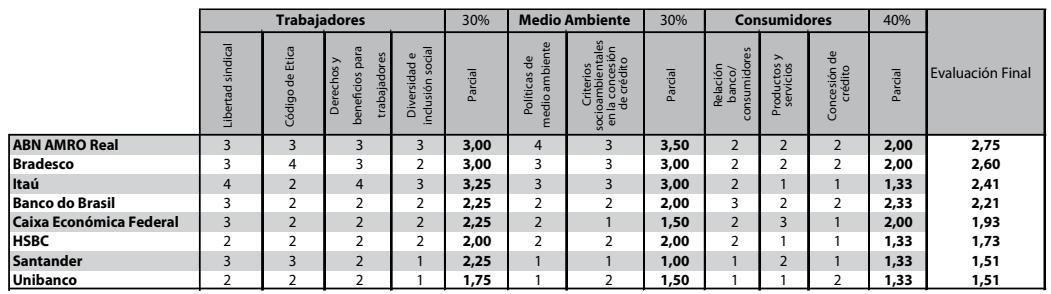

Además, esta empresa es consistente en cuanto a los criterios socioambientales que emplea para la concesión de créditos.

En el caso del Banco Bradesco, se presentan indicadores consistentes de sustentabilidad y realización de acciones ambientales, infelizmente restringidas a algunas agencias y a la administración. También se afirma que analizan el riesgo ambiental, pero no presentan detalles sobre este tipo de prácticas. La implementación de la RSE de esta institución financiera recibió la calificación de «regular», aunque la peor calificación en el tema ambiental fue ocupada por el Santander. Por su parte, el HSBC registra políticas en el ámbito internacional, aunque no existe información concreta sobre acciones en Brasil, motivo que perjudica su evaluación en este criterio.

Respecto a la relación banco-consumidor, la investigación enfatizó las instituciones financieras que poseen canales para relacionarse con sus clientes y atender sus necesidades. El Banco de Brasil presentó datos detallados de reclamos y demostró poseer un sistema de monitoreo para estos casos. Unibanco y Santander obtuvieron las evaluaciones más bajas por presentar, en sus respuestas, indicios de una postura defensiva, conforme se ve en la encuesta. En general, en el tema de consumidores, los bancos recibieron las peores calificaciones, pero sería importante continuar investigando para verificar divergencias entre el discurso y la práctica.

Con los resultados parciales, se realizó la ponderación final de las evaluaciones y se encontró que dos bancos ocupan la calificación de «regular»: ABN Amro Real y Bradesco, con una valoración menor a 3 pero mayor a 2.5. En la calificación de «mal nivel» de desarrollo de las actividades de RSE, se registran cuatro bancos en el intervalo de valoración entre 1.5 y 2.5: Itaú, Banco do Brasil, Caixa Económica Federal y HSBC. Los bancos Santander y Unibanco obtuvieron la calificación de «pésimo», con valoraciones entre 1 y 1.5 .

\section{II.2. Banca comercial en el Perú: 2007-2009}

Antes de detallar la evaluación de la situación de la RSE en la banca comercial del Perú y de realizar la comparación de su evolución entre 2007 y 2009, se presenta una breve reseña de las actividades llevadas a cabo por cada empresa analizada. Dentro de su institución, el BCP ha

ANÁLISIS COMPARATIVO DE LA RESPONSABILIDAD SOCIAL EN EL SECTOR FINANCIERO: ESTUDIOS DE CASO EN PERÚ Y BRASIL 2007-2009 
construido a los niveles máximos posibles una cultura de compromiso respecto del apoyo y la retribución a la comunidad; en cuanto a sus trabajadores, lo ha hecho «en el nivel justo», tal y como lo define Dionisio Romero Paoletti, presidente de su directorio ${ }^{4}$. Esta empresa cuenta con una gestión para resultados que se enfoca en mejorar el vínculo con su entorno social, lo cual abarca aspectos educativos, culturales, sociales y deportivos. Cabe destacar que el banco tiene como una línea de acción la contratación de personas con síndrome de Down, además de que todo su personal forma parte del voluntariado.

En 2007, sin embargo, se presentaron problemas en cuanto a la relación con algunos clientes. El BCP aprovechaba su solidez financiera para ofrecer tasas de interés en ahorros (tasa pasiva) más bajas que el promedio de los bancos. Al mismo tiempo, se detectó que estaba empeñado en ofrecer, a través de sus canales de atención al cliente, productos enganchados con las cuentas de ahorro, sin identificar quién los necesitaba realmente (microseguros de vida, de robo de tarjeta y de desempleo). Asimismo, no registró sindicato alguno y la dirección no se pronunció respecto del tema.

Con respecto al año 2007, la empresa ha mejorado su servicio. Se preocupó por ampliar y mejorar sus canales de atención virtuales (Internet) e indirectos (agentes de atención en farmacias y otros centros comerciales en horario extendido). Además, ha mantenido sus políticas de acción concreta a través de la ayuda a los sectores a los cuales apoyó durante la última década, al llevar a cabo importantes iniciativas como el programa 20 en Mate. En la relación con los trabajadores no se han registrado importantes conflictos, pero aún no cuentan con sindicatos y conservan bajos promedios de edad en sus agencias de atención al público. Con respecto a las tasas de interés, el BCP ha hecho un importante esfuerzo por crear nuevos productos de ahorro exentos de comisiones, un aporte significativo a la bancarización del país.

El BBVA - Banco Continental del Perú presenta un concepto de RSE más ligado a la filantropía y enganchado con la posición global de la empresa. La institución cuenta con una fundación ${ }^{5}$ a través de la cual realiza actividades y obras de contribución directa con la sociedad. No ha habido mayores cambios respecto de 2007 en este sentido.

Otro punto resaltante es que la visión de sus trabajadores respecto a la RSE se inscribe en un nivel teórico notable y muy identificado con el rol como transnacional presente en el país. Sin embargo, se nota que no reconocen el vínculo con las acciones que la corporación condujo como transnacional en otros países respecto de su política de préstamo a corporaciones de dudoso actuar.

4 En <http://www.viabcp.com/zona_publica/04_banco/index.asp?SEC=4\&JER=1462>. Fecha de consulta: 4 de enero de 2010.

5 En <http://www.bbvabancocontinental.com/tlpu/jsp/pe/esp/conocN/quien/fundabbvabancontin/index. jsp>. Fecha de consulta: 4 de enero de 2010. 
El BBVA en el Perú cuenta con un sindicato, pero los trabajadores afiliados constituyen una minoría y son, sobre todo, herederos de las grandes organizaciones sindicales de los años ochenta. Las altas cargas horarias manifestadas anónimamente por empleados de diferentes agencias y posiciones -incluso se habla de más de doce horas de permanencia dentro del local de trabajo- representan un problema grave. El portal web no muestra su política de RSE específica para el país y no se registran compromisos visibles sobre medio ambiente y consumidores. A su vez, la relación con sus clientes presenta matices diferentes. Si bien, por un lado, sus tarjetas de crédito no mantienen tasas diferentes de las más altas del mercado para los sectores con mayor riesgo —en los que podría aprovecharse el hecho de ser una institución sólida, a diferencia de bancos y financieras más pequeños-, por otro lado ofrecen al público la posibilidad de financiar más del $100 \%$ del valor de un préstamo hipotecario o automotriz, generalmente con tasas de las más bajas del mercado peruano.

Hacia el año 2007, según comunicaciones con funcionarios del banco, en Scotiabank la RSE recién se estaba implementando y, por ello, no contaba con una organización alrededor del tema. Esto, sin embargo, no impidió que se hayan realizado contribuciones a la sociedad. A pesar de ello, su política para el desarrollo de la cultura organizacional en torno a la RSE es aún incierta.

Scotiabank posee un sindicato de trabajadores que fue heredado del Wiese Sudameris, banco constituido a partir de la fusión de dos importantes instituciones financieras de los años ochenta. El sindicato mantiene un diálogo permanente con las autoridades administrativas del banco, pero no recibe apoyo para consolidarse dentro de la organización. Con la absorción del Banco del Trabajo, convertido en la financiera CrediScotia, el banco asumió un nuevo sindicato de trabajadores; resulta destacable que este sindicato no haya sido anulado.

En cuanto a la relación con sus clientes, en 2009 esta empresa presentó nuevos canales de atención. Se ha preocupado por seguir el avance de los otros dos bancos líderes en el sistema, y con ello ha mejorado la calidad de su atención: en este sentido, se nota la relevancia de la competencia generada a partir del liderazgo del BCP. Por otro lado, Scotiabank no tiene compromisos explícitos ni una política claramente definida sobre políticas medioambientales, aunque ha comenzado a darle alguna importancia al tema.

Interbank, a diferencia de los anteriores bancos, cuenta con una interesante percepción en torno al tema de la RSE, a pesar de que no posee una organización ad hoc ni un enfoque claro. Por ejemplo, la institución se preocupa de que sus trabajadores hagan voluntariado, aunque de forma dispersa y sin un objetivo de largo plazo. Este banco no cuenta con sindicatos ni tampoco con una política que motive su aparición.

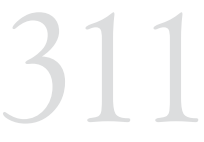

ANÁLISIS COMPARATIVO DE LA RESPONSABILIDAD SOCIAL EN EL SECTOR FINANCIERO: ESTUDIOS DE CASO EN PERÚ Y BRASIL 2007-2009 
A partir de esta información y del desarrollo de los cuestionarios, se procedió a realizar una calificación de la situación de estos bancos con respecto a la RSE.

En el cuadro 6 se comparan los bancos con respecto a sus actividades de responsabilidad social para el año 2007. Se observa que Interbank alcanza la calificación de 2.4 (más alta), seguido por el BCP y el Banco Continental, y en último lugar se halla Scotiabank. Los cuatro lograron la calificación «mala» — según la escala del cuadro 4-, lo que implica un escaso desarrollo de la RSE entre sus actividades. La evaluación del criterio de medio ambiente no ha sido clave, pues ninguno de los bancos ha logrado sumar algún puntaje en criterios socioambientales.

Cuadro 6. Calificaciones de los casos peruanos 2007

\begin{tabular}{|c|c|c|c|c|c|c|c|c|c|c|c|c|c|}
\hline & \multicolumn{4}{|c|}{ Trabajadores } & \multicolumn{3}{|c|}{\begin{tabular}{l|l}
0,3 & Medio Ambiente
\end{tabular}} & \multirow{2}{*}{$\begin{array}{l}0,3 \\
\\
\overline{\frac{\pi}{50}} \\
\frac{5}{0}\end{array}$} & \multicolumn{3}{|c|}{ Consumidores } & \multirow{2}{*}{\begin{tabular}{|c|}
$40 \%$ \\
\\
$\frac{\bar{\sigma}}{50}$ \\
\end{tabular}} & \multirow[t]{2}{*}{\begin{tabular}{|c|}
$\begin{array}{c}\text { Evaluación } \\
\text { Final }\end{array}$ \\
\end{tabular}} \\
\hline & 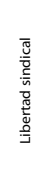 & 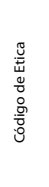 & 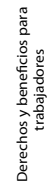 & 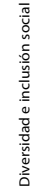 & 嵒 & 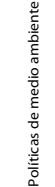 & 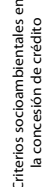 & & 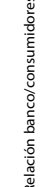 & 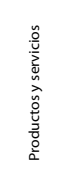 & 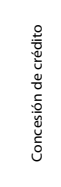 & & \\
\hline$B C P$ & 1,00 & 3,00 & 3,00 & 2,50 & 2,38 & 3,50 & 0,00 & 1,75 & 3,20 & 3,00 & 2,00 & 2,73 & 2,33 \\
\hline \begin{tabular}{|l|} 
Continental \\
Scotiabank
\end{tabular} & $\begin{array}{l}3,00 \\
200\end{array}$ & $\begin{array}{l}3,00 \\
1,00 \\
100\end{array}$ & $\frac{2,00}{3}$ & $\begin{array}{l}3,00 \\
3,00 \\
3.00\end{array}$ & $\frac{2,75}{225}$ & $\begin{array}{l}2,000 \\
3000\end{array}$ & $\frac{0,00}{0.00}$ & 1,00 & 3,00 & \begin{tabular}{|l|}
2,90 \\
\end{tabular} & 3,10 & $\frac{3,00}{280}$ & 2,33 \\
\hline $\begin{array}{l}\text { SSotiabank } \\
\text { Interbank }\end{array}$ & $\frac{2,00}{1,00}$ & $\frac{1,00}{2,00}$ & $\frac{3,30}{2,80}$ & $\frac{3,00}{3,00}$ & $\frac{2,25}{2,20}$ & $\frac{3,00}{3,50}$ & $\begin{array}{l}0,000 \\
0,00\end{array}$ & $\frac{\frac{1,10}{1,75}}{2}$ & $\begin{array}{l}3,00 \\
3,00 \\
-10\end{array}$ & \begin{tabular}{|l|}
2,90 \\
3,20 \\
\end{tabular} & $\frac{2,30}{3,00}$ & \begin{tabular}{|l|l|l|l}
2,80 \\
3,07
\end{tabular} & $\frac{2,25}{2,41}$ \\
\hline
\end{tabular}

En el cuadro 7 se observan los resultados para 2009. Los cuatro casos analizados mantienen la calificación de «mala situación» respecto a la RSE. En la comparación de los bancos evaluados con respecto a sus actividades de responsabilidad social, Interbank alcanza la calificación más alta, con 2,5, incluso mayor a la de 2007. Le siguen el BCP y el Banco Continental, que también mejoraron su calificación respecto de 2007. En el caso del BCP, la mejora se debió a la contribución de su código de ética, y a la diversidad e inclusión social en aumento, ante la apertura de nuevas áreas enfocadas en el sector de microfinanzas.

En el caso del Banco Continental no se han observado mejoras sustanciales; sin embargo, tampoco ha habido retrocesos. El último lugar dentro de los cuatro casos analizados lo ocupa Scotiabank, que incluso empeora en sus prácticas medioambientales, aunque mejora en su relación con los consumidores, producto de la buena performance de su tarjeta Única y de su ingreso en el sector de la microempresa con CrediScotia, ello a pesar de haber heredado los problemas del sindicato del ex Banco del Trabajo.

Finalmente, se realiza una comparación entre ambos períodos en el gráfico 1. Las barras blancas muestran los valores de calificación de los bancos peruanos en 2007, y las columnas grises en 2009. La comparación entre ambos años se sujeta a la calificación alcanzada por los bancos en 


\begin{tabular}{|c|c|c|c|c|c|c|c|c|c|c|c|c|c|}
\hline & \multicolumn{4}{|c|}{ Trabajadores } & \multirow[b]{2}{*}{$\begin{array}{l}30 \% \\
\\
\\
\\
\frac{\pi}{\overline{0}} \\
\frac{\pi}{0} \\
\end{array}$} & \multicolumn{2}{|c|}{$\begin{array}{c}\text { Medio } \\
\text { Ambiente }\end{array}$} & \multirow[b]{2}{*}{ 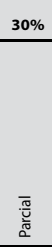 } & \multicolumn{3}{|c|}{ Consumidores } & \multirow[b]{2}{*}{\begin{tabular}{|c|}
$40 \%$ \\
\\
\\
\\
$\frac{\bar{\pi}}{50}$ \\
$\frac{\pi}{0}$ \\
\end{tabular}} & \multirow[b]{2}{*}{ 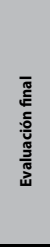 } \\
\hline & 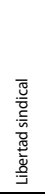 & 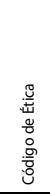 & 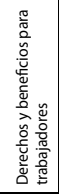 & 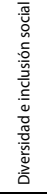 & & 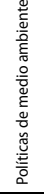 & 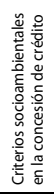 & & 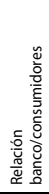 & 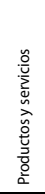 & 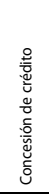 & & \\
\hline$B C P$ & 1,00 & 3,10 & 3,00 & 2,70 & 2,45 & 3,50 & 0,00 & 1,75 & 3,30 & 3,10 & 2,00 & 2,80 & 2,38 \\
\hline \begin{tabular}{|l|} 
Continental \\
\end{tabular} & 3,00 & 3,00 & 2,00 & 3,00 & 2,75 & 2,00 & 0,00 & 1,00 & 3,00 & 2,90 & 3,10 & 3,00 & 2,33 \\
\hline \begin{tabular}{|l|} 
Scotiabank \\
\end{tabular} & 1,80 & 1,00 & 3,00 & 3,00 & 2,20 & 3,10 & 0,00 & 1,55 & 3,10 & 2,90 & 2,50 & 2,83 & 2,26 \\
\hline Int erbank & 1,00 & 2,00 & 3,20 & 3,00 & 2,30 & 3,50 & 0,00 & 1,75 & 3,20 & 3,20 & 3,20 & 3,20 & 2,50 \\
\hline
\end{tabular}

el concepto de RSE, donde se observa que ninguno de ellos sobrepasa la valla superior a 2.5, lo que los hace merecedores, en general, a una calificación de «malo-regular» en la aplicación del concepto. Sobre la base de los resultados, se puede concluir que las instituciones financieras han avanzado muy poco en cuanto a la implementación de políticas que impliquen acciones permanentes referidas a medio ambiente y a atención de consumidores y trabajadores.

\section{Gráfico 1}

Perú: Análisis comparativo de las Calificaciones asignadas en el caso, 2007-2009

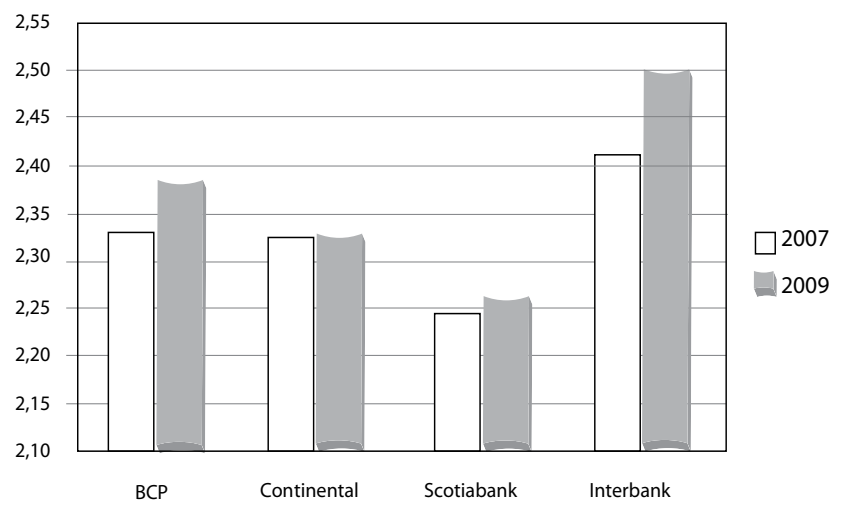

\section{II.3. Comparación de la RSE en la banca comercial de Perú y Brasil para 2007}

Finalmente, se puede realizar una comparación entre ambos países con los datos de 2007, conforme se observa en el gráfico 2. La imagen de la izquierda muestra los valores de calificación de los bancos de Brasil, mientras que el gráfico de la derecha registra la calificación de los peruanos. La comparación entre ambos países se sujeta a la calificación alcanzada por los bancos en el concepto de RSE, donde Perú no sobrepasa los
ANÁLISIS COMPARATIVO DE LA RESPONSABILIDAD SOCIAL EN EL SECTOR FINANCIERO: ESTUDIOS DE CASO EN PERÚ $Y$ BRASIL 2007-2009 
límites de una mala situación de implementación de RSE. En el caso de Brasil, se encuentran dos bancos con calificación superior a 2.5, lo cual los hace merecedores de una calificación de «regular» en la aplicación del concepto RSE.

\section{Gráfico 2: Análisis comparativo de las Calificaciones asignadas en los casos de Brasil y Perú}
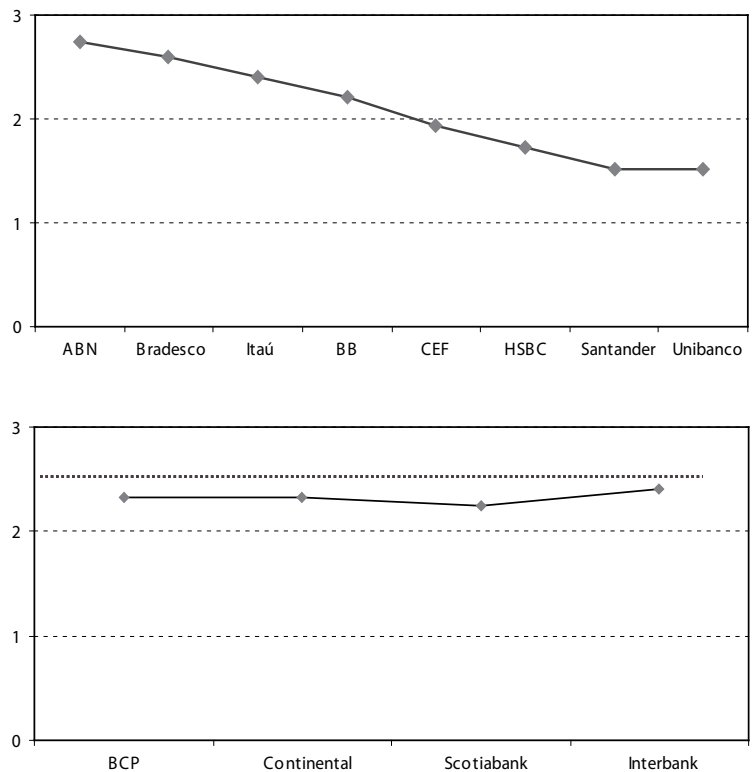

\section{CONCLUSIONES GENERALES}

Aunque la RSE gana terreno en la región y muestra ser un mecanismo eficaz para reducir costos y fortalecer la cuota de mercado en el mediano plazo, muchas empresas se han mostrado reticentes a adoptar prácticas relacionadas con ella. Por otra parte, se puede observar que, en los últimos años, los bancos en el Perú han trabajado en la mejora del concepto de RSE, ante lo cual generaron una posición institucional más comprometida con la sociedad.

Aun cuando las empresas estudiadas están afiliadas a iniciativas globales y a otros medios de control para la mejora sobre prácticas de RSE, este concepto todavía aparece muy relacionado a la filantropía y a la generosidad.

Las cuatro entidades financieras analizadas en el Perú tienen clara la importancia de contar con más información sobre iniciativas, experiencias y fundamentos de responsabilidad social, pero su aplicación y su concordancia con la política institucional aún tiene un largo camino por 
recorrer, pues se deja notar que «sale de un área del banco contratada para eso» y no corresponde a una visión estratégica de sus hacedores de política y prospectiva, sino al campo de lo «políticamente correcto».

Otra conclusión de este trabajo es que los instrumentos metodológicos de análisis de la RSE deben ser perfeccionados para que se puedan consolidar los parámetros en orden a sistematizar las experiencias a nivel internacional, especialmente en instituciones bancarias, y favorecer así a un mayor flujo de consumidores. En futuras evaluaciones, los criterios deberán ser más rígidos y las preguntas deberán dar más espacio a la descripción de acciones, de forma tal que los encuestados puedan mostrar una diversidad de iniciativas y, en consecuencia, faciliten a los evaluadores las condiciones para detectar diferencias sutiles, pero importantes, en el comportamiento socialmente responsable de las instituciones.

Asimismo, las próximas investigaciones sobre el tema deberán admitir mayor interacción por parte de los bancos, reacios hoy a su evaluación, de manera que las prácticas señaladas en los casos analizados puedan ser mejoradas y que sea el inicio de la construcción de un espacio para la vigilancia social y el diálogo para una mejora continua de prácticas de RSE. 


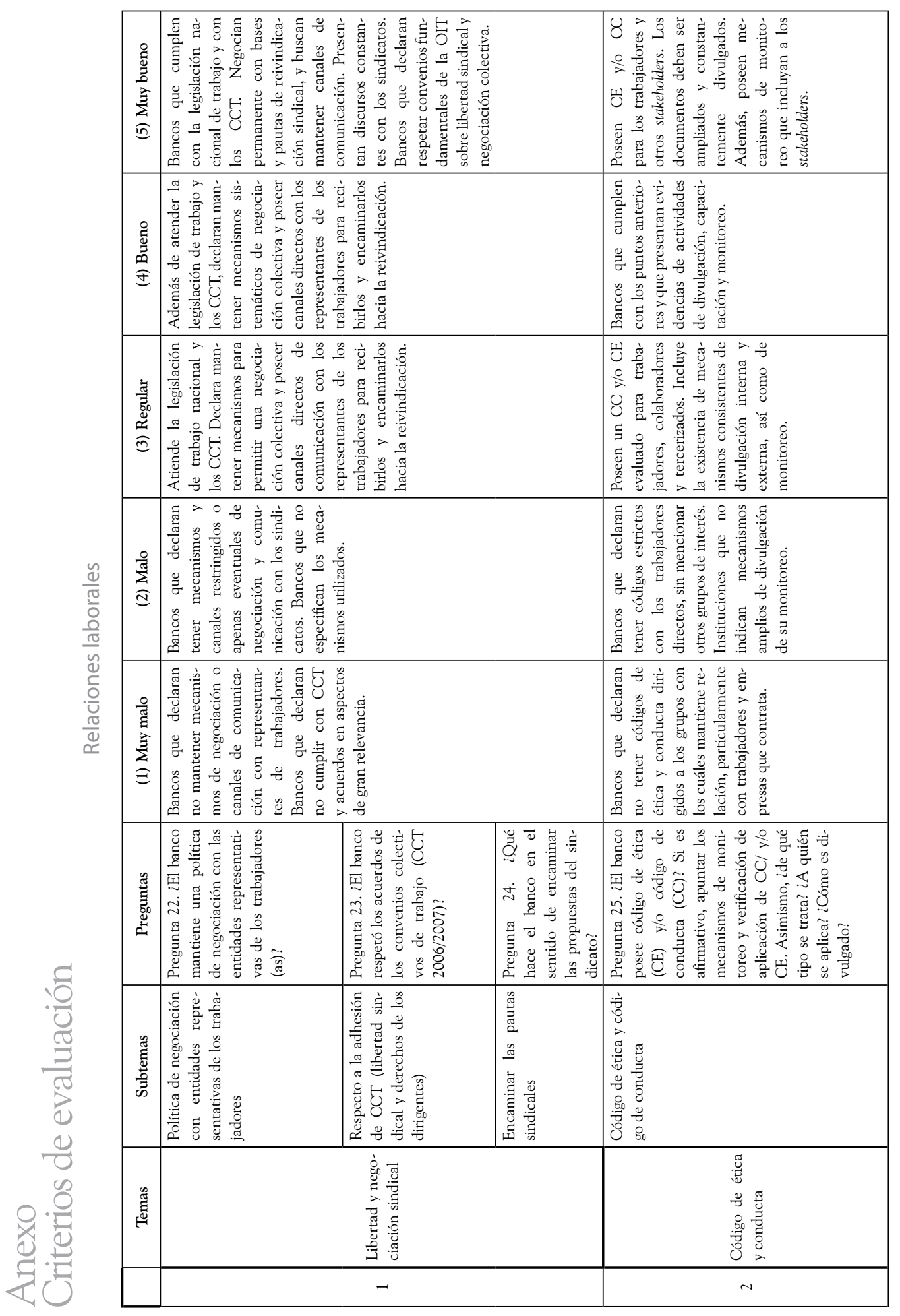




\begin{tabular}{|c|c|c|c|c|}
\hline & \multicolumn{4}{|c|}{ 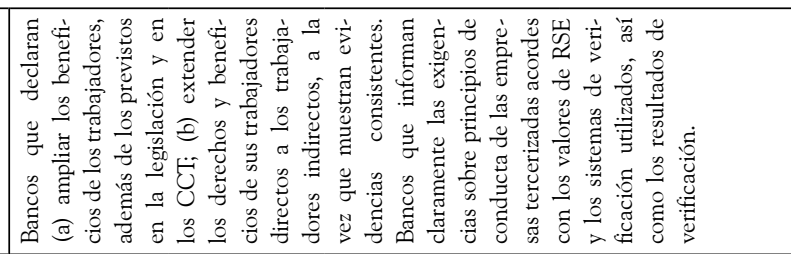 } \\
\hline & \multicolumn{4}{|c|}{ 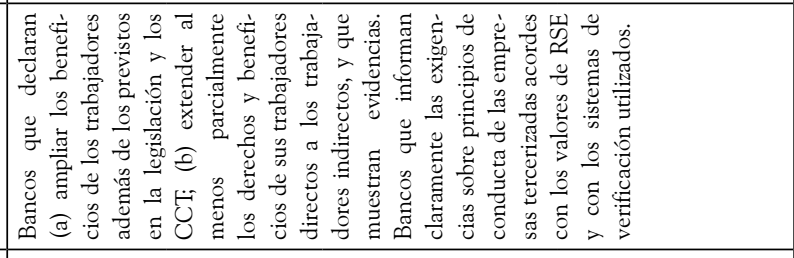 } \\
\hline 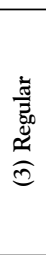 & \multicolumn{4}{|c|}{ 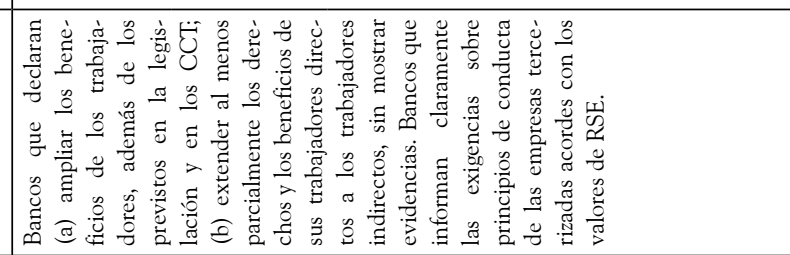 } \\
\hline$\sum_{a}^{\frac{a}{d}}$ & \multicolumn{4}{|c|}{ 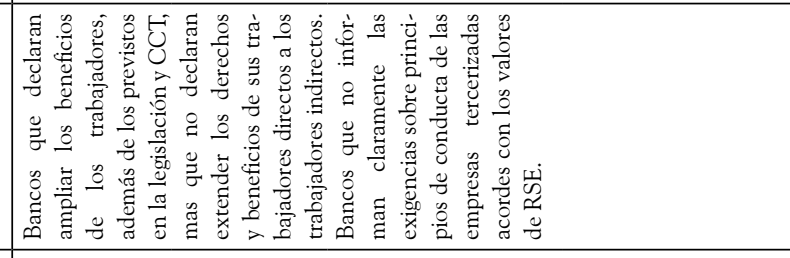 } \\
\hline$\sum_{\Xi}^{\stackrel{0}{E}}$ & \multicolumn{4}{|c|}{ 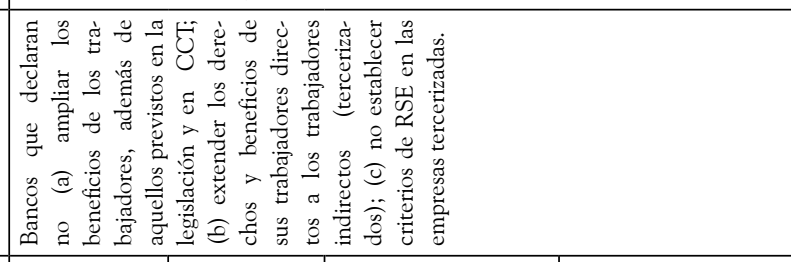 } \\
\hline & 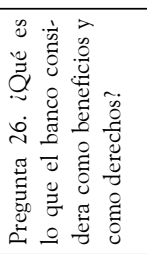 & 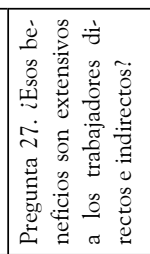 & 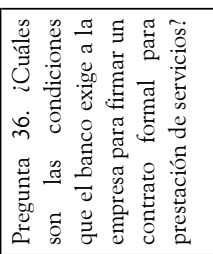 & 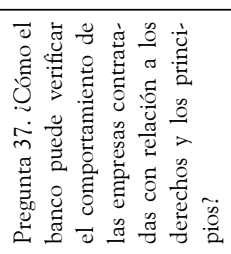 \\
\hline & \multicolumn{2}{|c|}{ 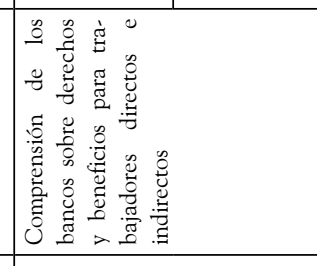 } & \multicolumn{2}{|c|}{ 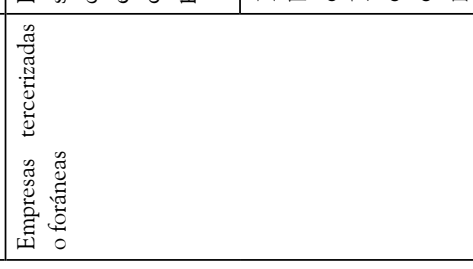 } \\
\hline \multirow[t]{2}{*}{ 总 } & \multicolumn{4}{|c|}{ 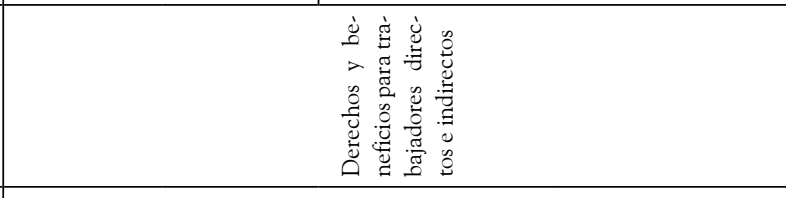 } \\
\hline & & & & \\
\hline
\end{tabular}




\begin{tabular}{|c|c|c|c|c|c|}
\hline 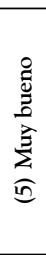 & \multicolumn{5}{|c|}{ 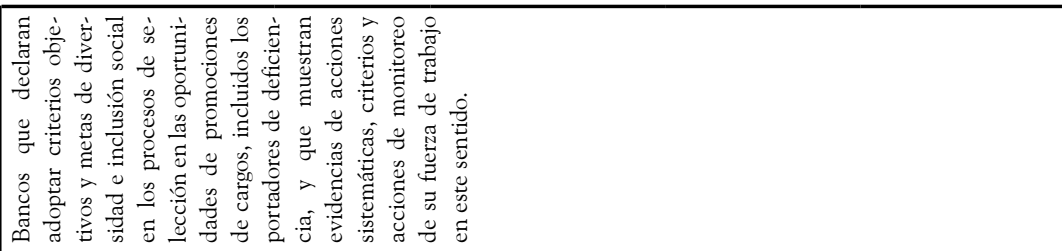 } \\
\hline 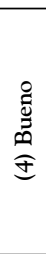 & \multicolumn{5}{|c|}{ 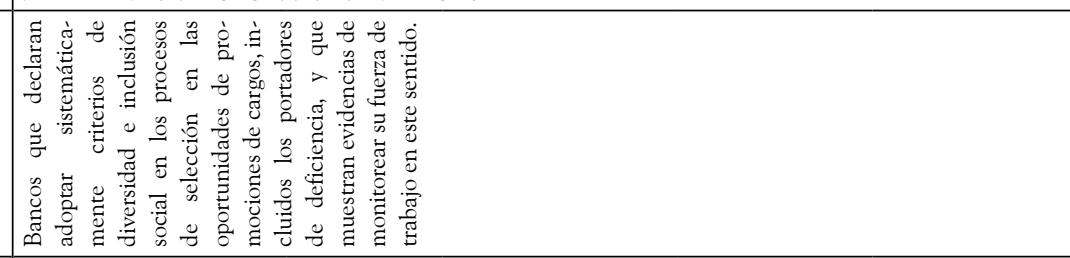 } \\
\hline 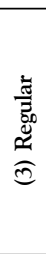 & \multicolumn{5}{|c|}{ 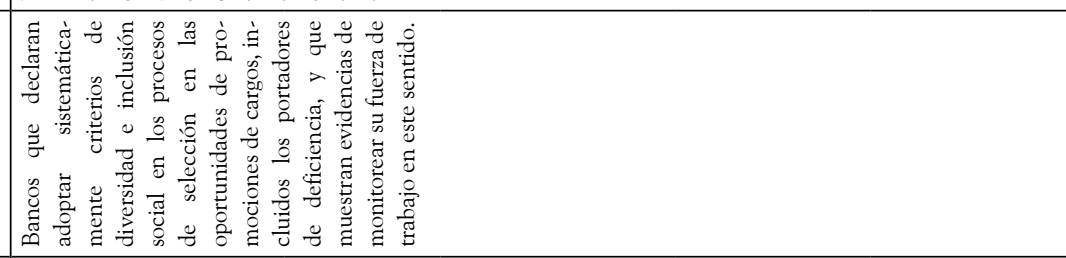 } \\
\hline 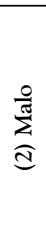 & \multicolumn{5}{|c|}{ 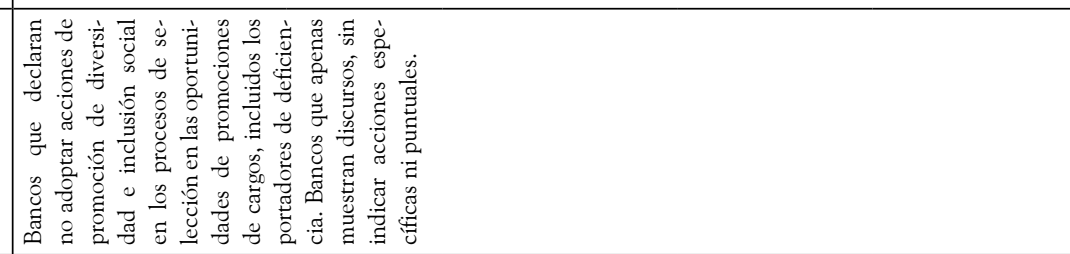 } \\
\hline 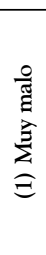 & \multicolumn{5}{|c|}{ 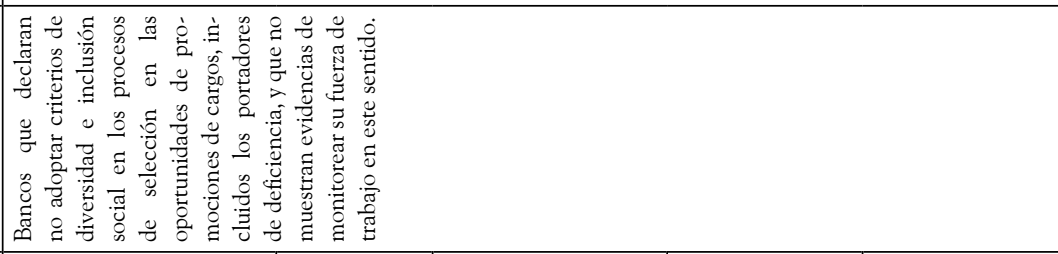 } \\
\hline 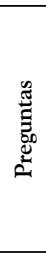 & 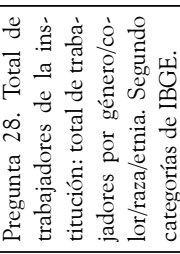 & 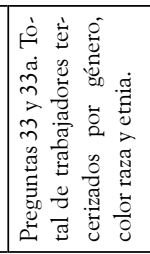 & 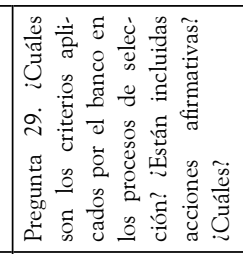 & 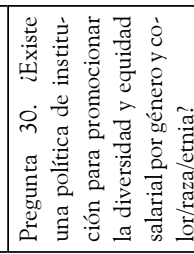 & 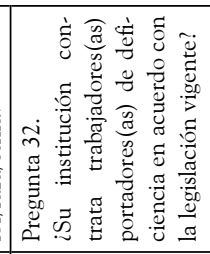 \\
\hline & \multicolumn{2}{|c|}{ 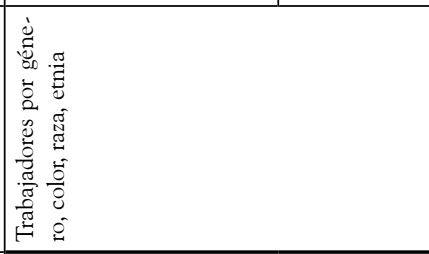 } & \multicolumn{2}{|c|}{ 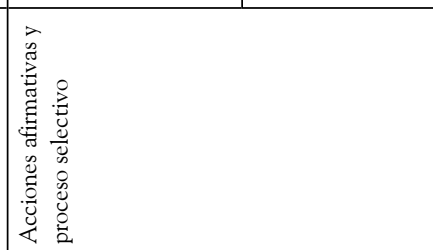 } & 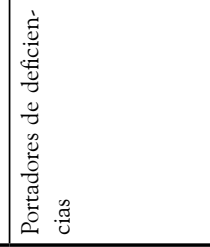 \\
\hline \multirow[t]{2}{*}{ 胥 } & \multicolumn{5}{|c|}{ 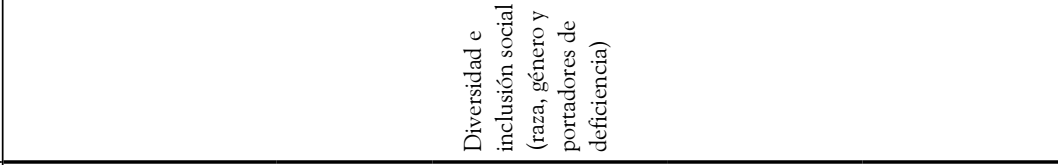 } \\
\hline & & & $\sigma$ & & \\
\hline
\end{tabular}




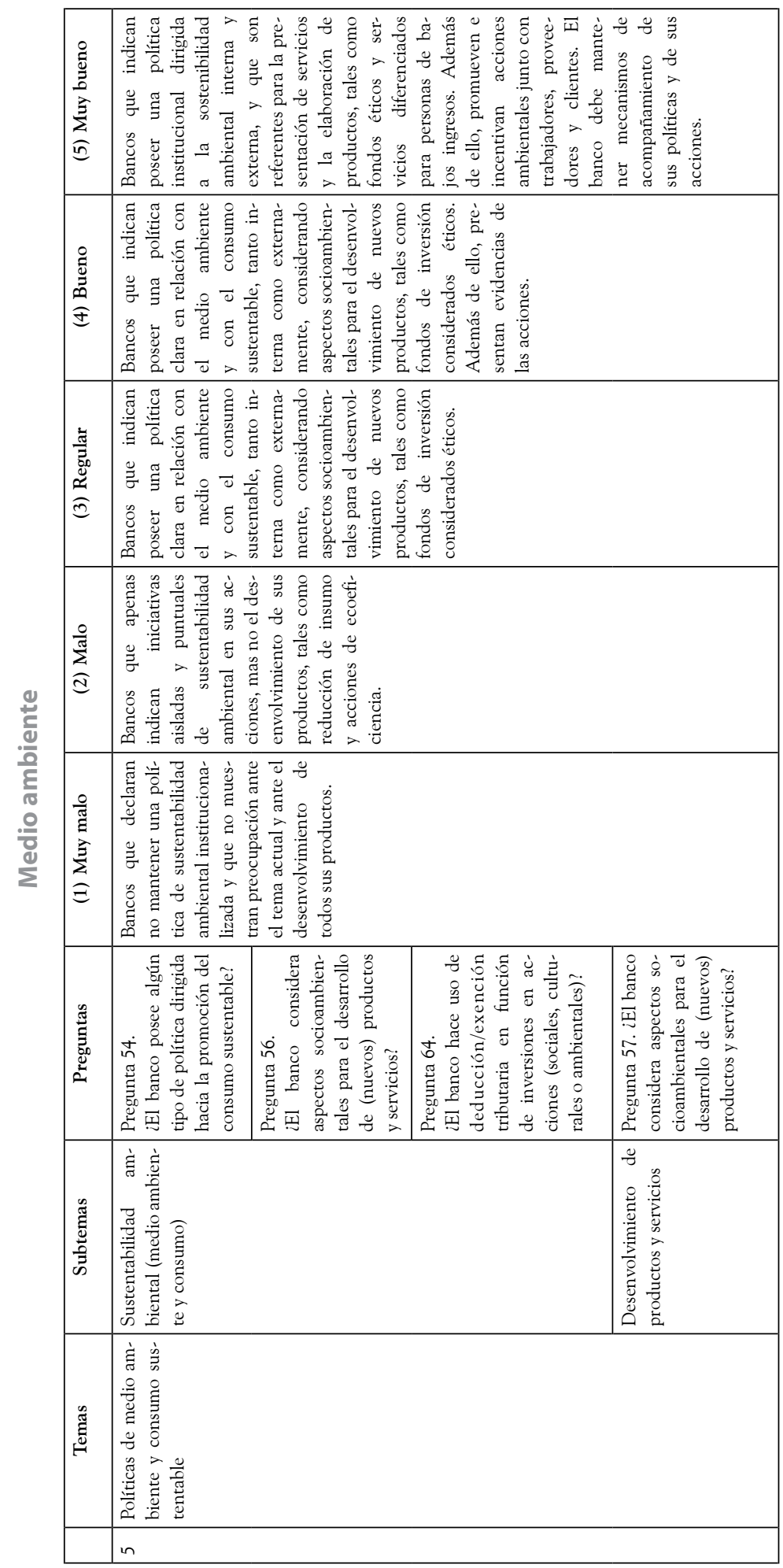




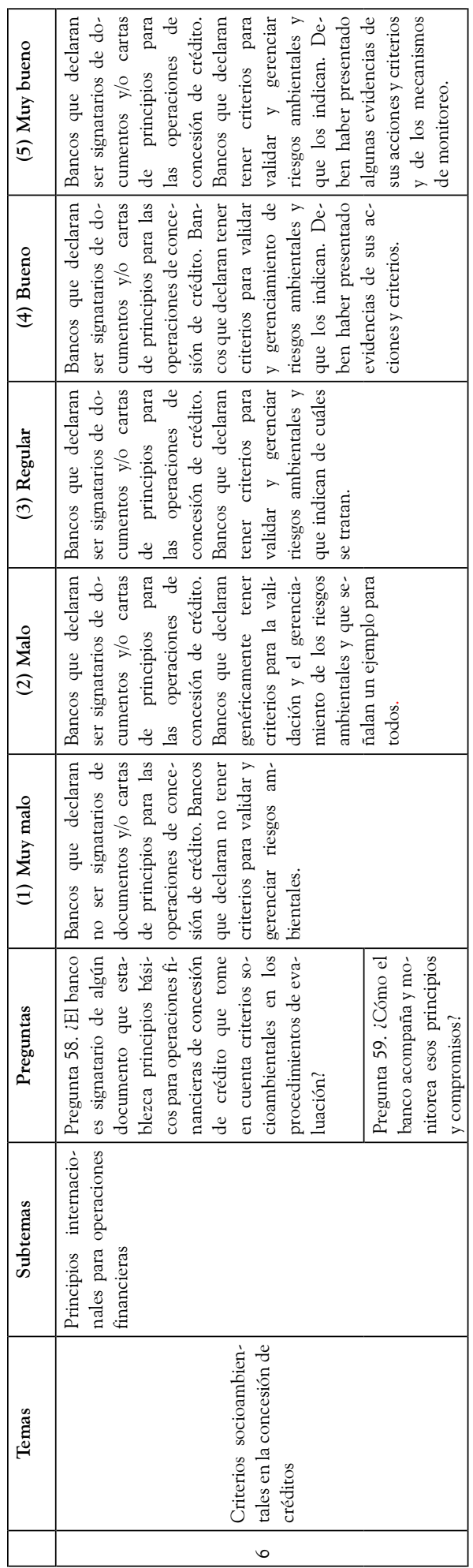




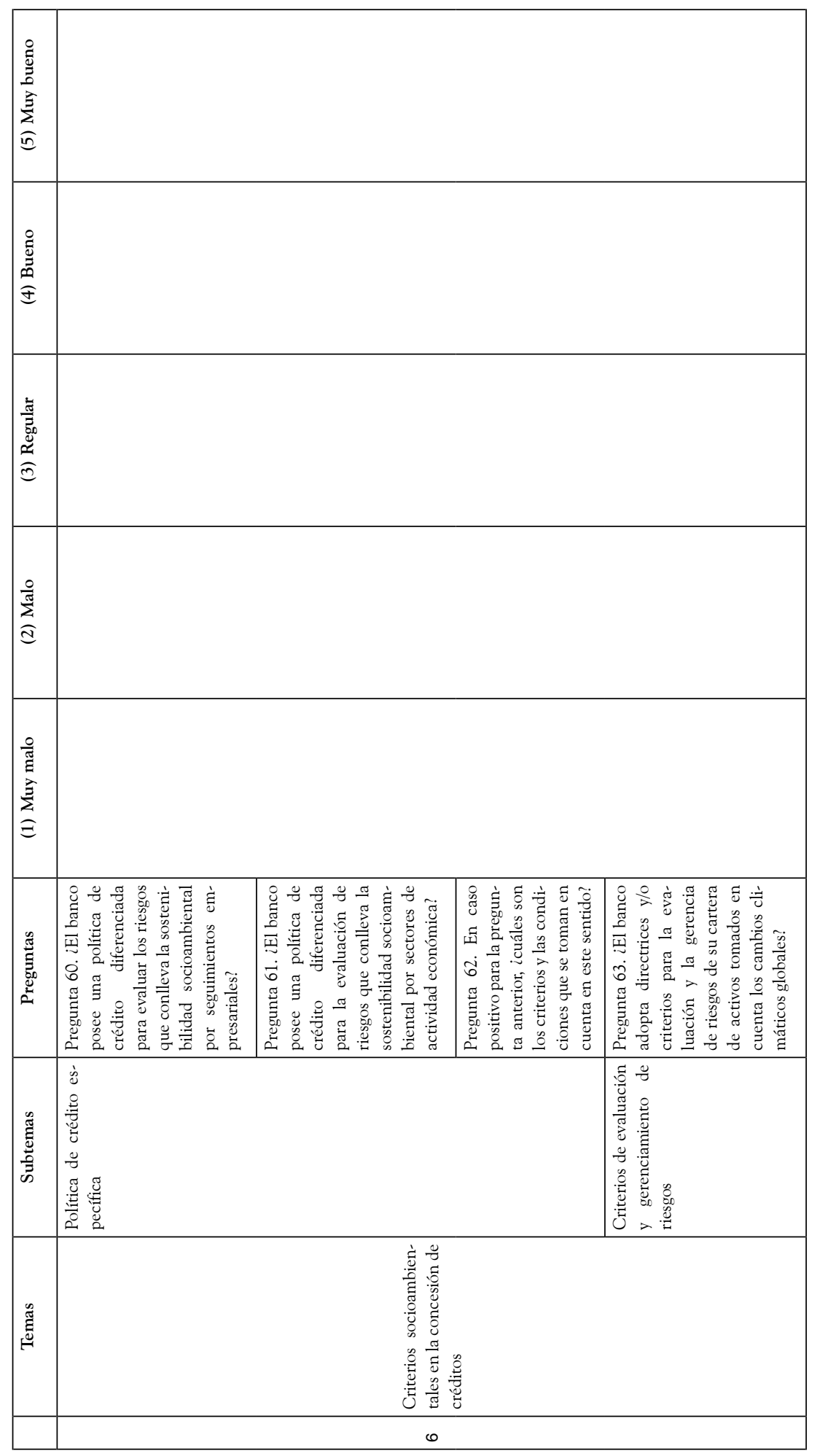




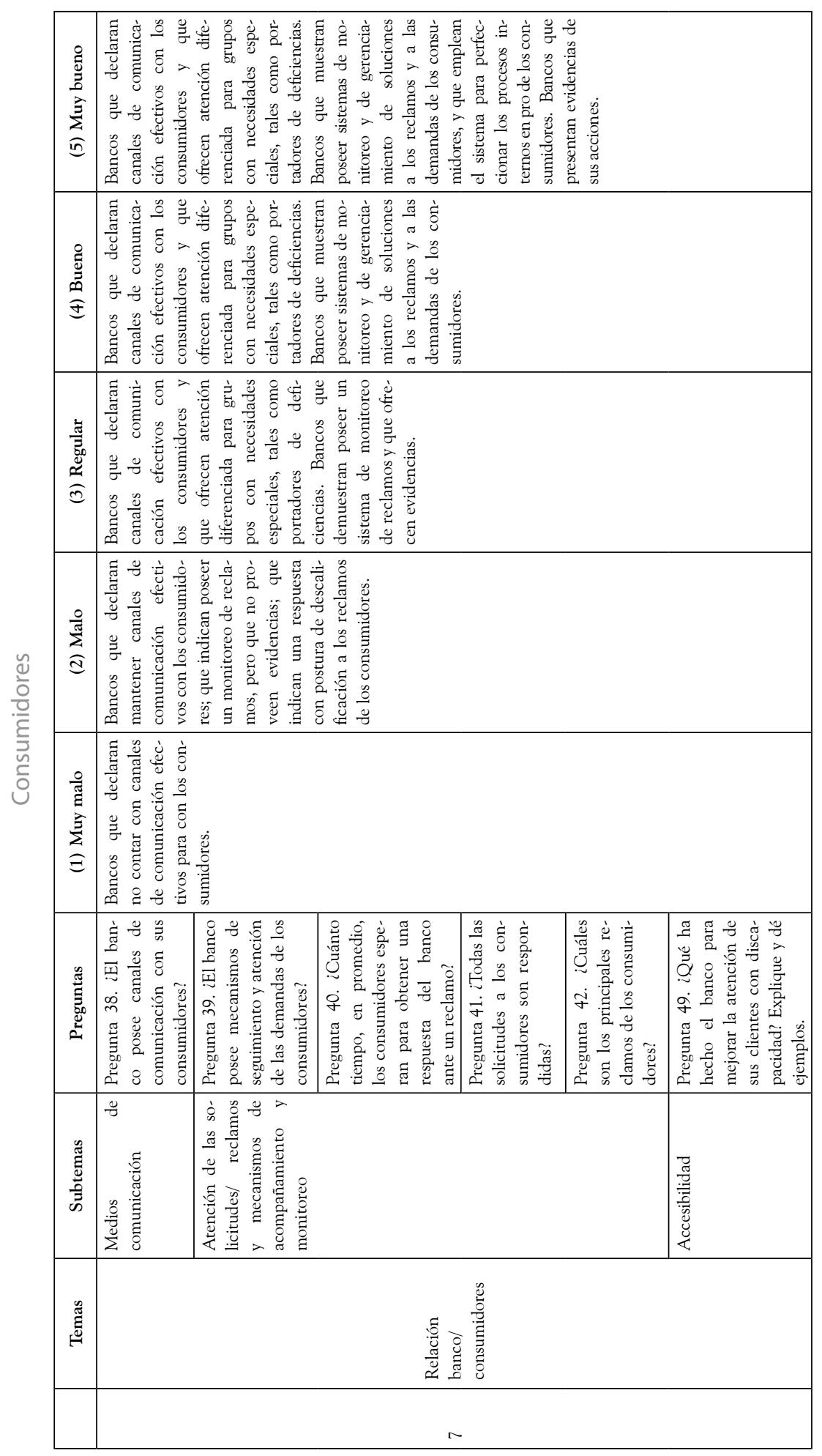




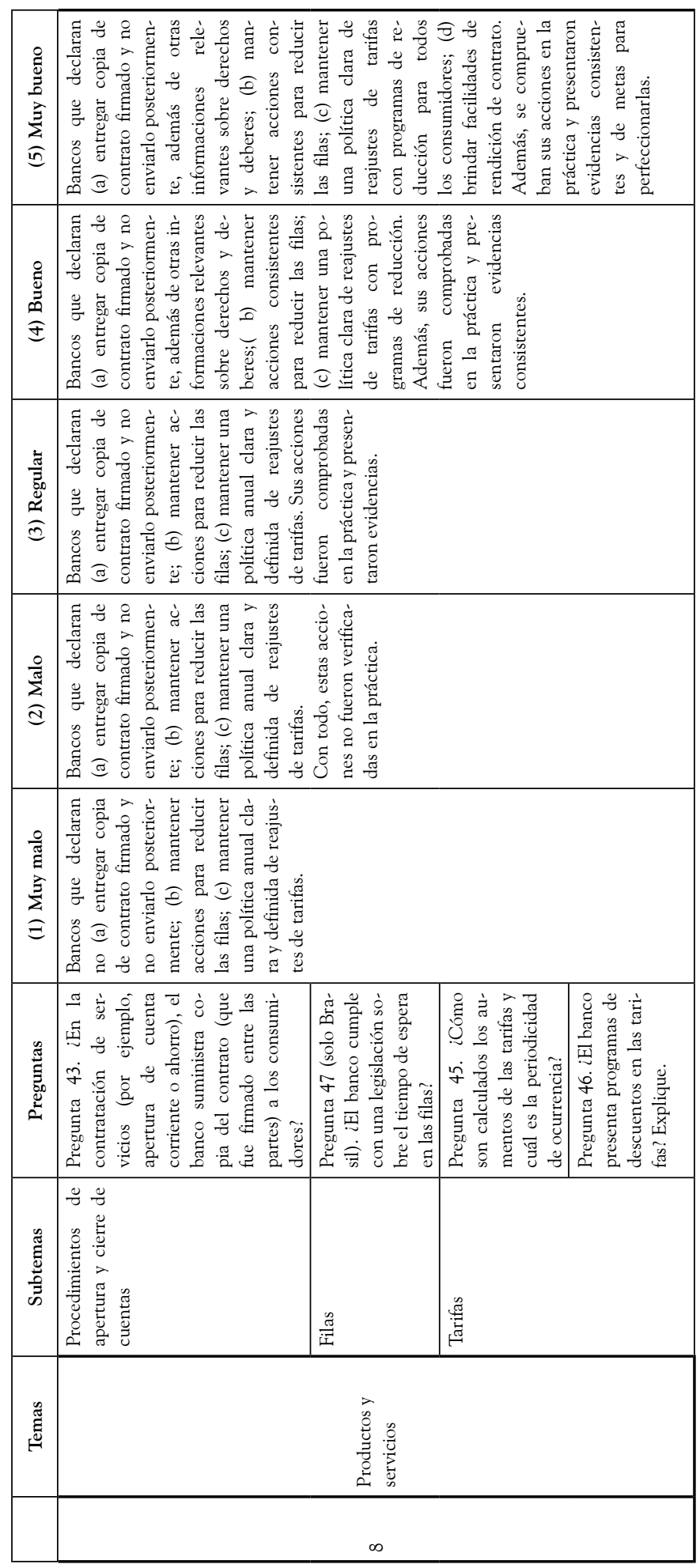




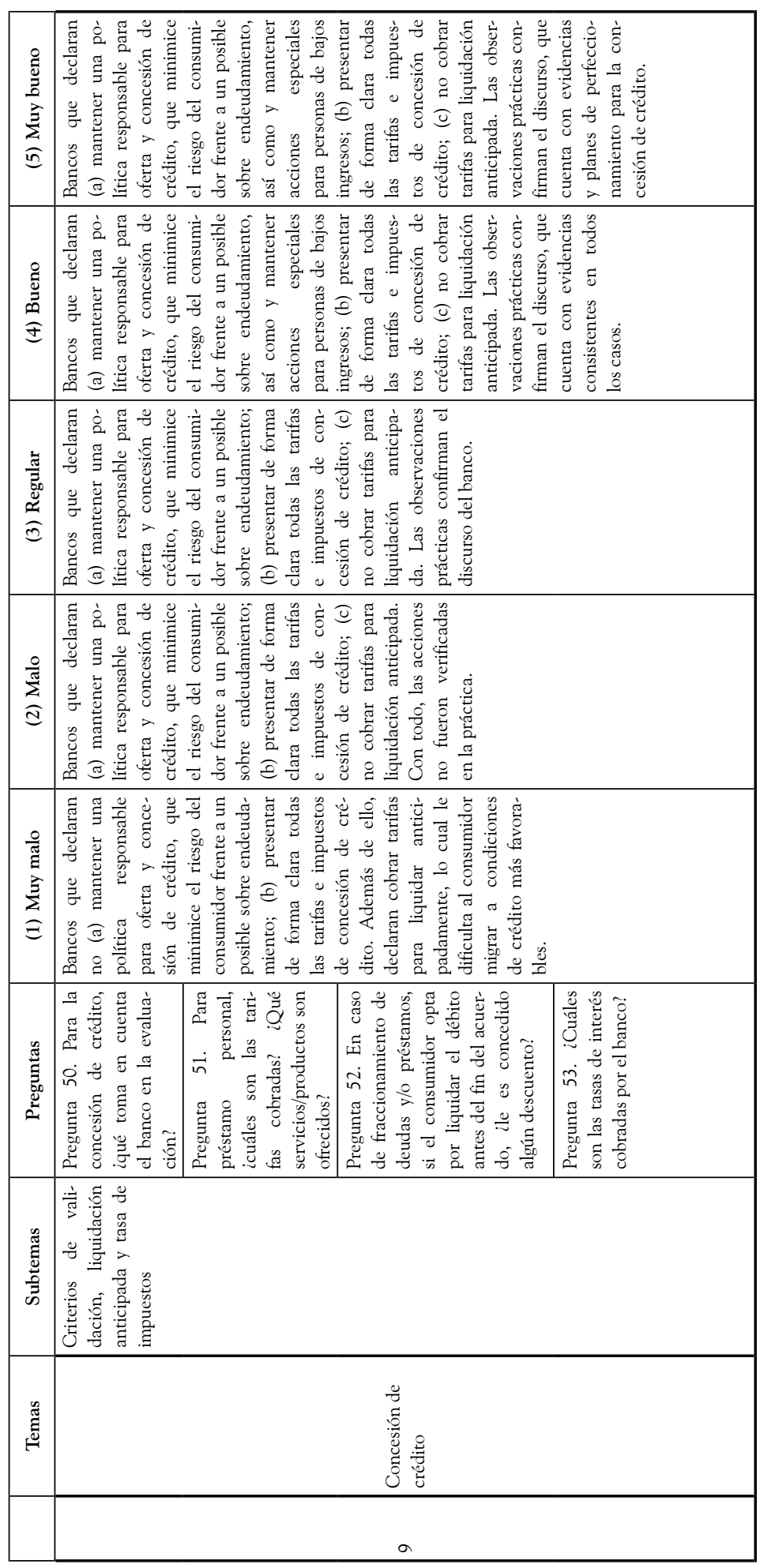

